\title{
Treatment and Prognosis of Radiation-Associated Breast Angiosarcoma in a Nationwide Population
}

\author{
Samuli H. Salminen, $\mathrm{MD}^{1,2}$ (1) , Tom Wiklund, $\mathrm{MD}, \mathrm{PhD}^{3}$, Mika M. Sampo, $\mathrm{MD}, \mathrm{PhD}^{4}$, Maija Tarkkanen, $\mathrm{MD}$, \\ $\mathrm{PhD}^{1,2}$, Lea Pulliainen, $\mathrm{MD}^{5}$, Tom O. Böhling, $\mathrm{MD}, \mathrm{PhD}^{6}$, Erkki Tukiainen, $\mathrm{MD}, \mathrm{PhD}^{2,5}$, \\ Katja Hukkinen, $\mathrm{MD}, \mathrm{PhD}^{2,7}$, and Carl P. Blomqvist, $\mathrm{MD}, \mathrm{PhD}^{1,2}$ \\ ${ }^{1}$ Comprehensive Cancer Center, Helsinki University Hospital, Helsinki, Finland; ${ }^{2}$ University of Helsinki, Helsinki, \\ Finland; ${ }^{3}$ Docrates Cancer Center, Helsinki, Finland; ${ }^{4}$ Department of Pathology, University of Helsinki and HUSLAB, \\ Helsinki University Hospital, Helsinki, Finland; ${ }^{5}$ Department of Plastic Surgery, Helsinki University Hospital, Helsinki, \\ Finland; ${ }^{6}$ Department of Pathology, University of Helsinki, Helsinki, Finland; ${ }^{7}$ Department of Radiology, Helsinki \\ University Hospital, Helsinki, Finland
}

\begin{abstract}
Background. Radiation-associated angiosarcoma of the breast (RAASB) is an aggressive malignancy that is increasing in incidence. Only a few previous populationbased studies have reported the results of RAASB treatment.

Methods. A search for RAASB patients was carried out in the Finnish Cancer Registry, and treatment data were collected to identify prognostic factors for survival.

Results. Overall, 50 RAASB patients were identified. The median follow-up time was 5.4 years (range 0.4-15.6), and the 5-year overall survival rate was $69 \%$. Forty-seven (94\%) patients were operated on with curative intent. Among these patients, the 5-year local recurrence-free survival, distant recurrence-free survival, and overall survival rates were $62 \%, 75 \%$, and $74 \%$, respectively. A larger planned surgical margin was associated with improved survival.

Conclusions. We found that the majority of RAASB patients were eligible for radical surgical management in this population-based analysis. With radical surgery, the prognosis is relatively good.
\end{abstract}

(C) The Author(s) 2019

First Received: 24 August 2019; Published Online: 26 November 2019

S. H. Salminen, MD

e-mail: samuli.h.salminen@helsinki.fi
Globally, breast cancer (BC) is the most commonly diagnosed cancer among women. ${ }^{1}$ Breast-conserving surgery combined with radiotherapy (RT) is the preferred local treatment of early-stage BC., ${ }^{2,3}$

Radiation-associated angiosarcoma of the breast (RAASB) is an uncommon severe complication of breast $\mathrm{RT}^{4}$ In recent years, angiosarcoma has been the most common subtype of radiation-associated sarcoma of the breast. ${ }^{5}$ A newly published population-based study estimated the risk of RAASB to be approximately $0.1 \% .^{6}$ It has been postulated that the shift from radical mastectomies to breast-conserving surgery has resulted in secondary angiosarcomas arising in the breast. ${ }^{7}$

The main treatment of RAASB is surgical excision if diagnosed in a localized stage $;^{8-14}$ however, different surgical approaches have previously been presented. It has been proposed that surgery should aim at resection of all previously irradiated skin $^{11}$ with negative margins. ${ }^{8}$ However, on the other hand, one study concluded that breastconserving surgery was non-inferior compared with mastectomy. ${ }^{10}$ In a previous study from our center, RAASB resection was aimed at a clinical side margin of more than $3 \mathrm{~cm}$; at last follow-up, six of nine patients were diseasefree. ${ }^{15}$ The benefit of adjuvant chemotherapy remains undetermined. ${ }^{14}$ In previous studies of RAASB, the 5-year overall survival (OS) rate has varied considerably, from $10 \%$ to $75 \%$, respectively, likely due to the substantial heterogeneity in RAASB treatment and study populations. $^{6,8,12,16,17}$ Most previously published research on RAASB treatment, except a recent population-based 
study, ${ }^{6}$ has mainly been performed in single tertiary cancer centers, which might have affected the results because of patient selection.

We set out to study the treatment and prognosis of RAASB in a Finnish nationwide population; RAASB patients were identified from the Finnish Cancer Registry (FCR). Treatment of localized RAASB was assessed and patients were followed for local or distant recurrences. Prognostic factors for local and distant recurrences, as well as OS, were analyzed.

\section{METHODS}

The FCR was searched for patients with previously diagnosed invasive BC (International Classification of Diseases for Oncology, Third Edition [ICD-O-3 $]^{18}$ ), and a subsequent angiosarcoma, during the period 1989-2014 (ICD-O-3 $3^{18}$ morphology 9120 , behavior 3), in, or close to, the breast or chest wall. The FCR was founded in 1952 and encompasses the entire population of Finland (currently approximately 5.6 million inhabitants). A regulation was administered by the National Board of Health in 1961 making the reporting of cancers to the FCR obligatory. BC and RAASB treatment data were gathered from treating hospitals. RAASB histopathology for the majority of cases was confirmed in a previous study. ${ }^{5}$

\section{Radiation-Associated Angiosarcoma of the Breast (RAASB) Treatment and Follow-Up Assessment}

Patient records and pathology reports were assessed to document the planned surgical side margins according to the surgery report $(\mathrm{cm})$, pathological surgical margins $(\mathrm{cm})$, removed tissues (skin, subcutaneous tissue, mammary gland, pectoral fascia, pectoral muscle), and possible surgical reconstruction. The pathological surgical margin was defined as the measurement stated in the original pathology report. Size (defined as the longest diameter of macroscopic tumor or skin lesion) and grade (according to the French system ${ }^{19}$ ) were documented. Preoperative and postoperative adjuvant chemotherapy and RT were registered. Patients were followed up for local recurrences and distant metastases, and possible deaths and causes of death were registered.

\section{Statistical Analyses}

Primary endpoints of the study were local recurrencefree survival (LRFS), distant recurrence-free survival (DRFS) and OS. LRFS was defined as the time from RAASB diagnosis to the first local recurrence; DRFS was defined as the time to first distant recurrence; and OS was defined as the time to death from any cause, with censoring at last follow-up. LRFS, DRFS, and OS were calculated using the Kaplan-Meier method, while prognostic factors for survival were analyzed using the Cox univariate model. IBM SPSS Statistics for Windows version 25 (IBM Corporation, Armonk, NY, USA) was used for all analyses.

\section{Ethics Approval and Consent to Participate}

This study was approved by the Joint Ethics Committee of Helsinki University Hospital and the Ministry of Health and Social Affairs. All procedures performed in studies involving human participants were in accordance with the ethical standards of the institutional research committee and with the 1964 Helsinki declaration and its later amendments or comparable ethical standards. Due to the retrospective nature of this study, the requirement for obtaining informed consent was waived with the permission of the Joint Ethics Committee of Helsinki University Hospital and the Ministry of Health and Social Affairs.

\section{RESULTS}

Our search of the FCR yielded a total of 50 patients with RAASB; all patients were Caucasian. BC characteristics and treatment data are shown in Table 1. All patients had received $\mathrm{RT}$ for $\mathrm{BC}$, and the majority had received a postoperative RT dose of $50 \mathrm{~Gy}$ in $2 \mathrm{~Gy}$ fractions $(n=38)$.

\section{RAASB Characteristics}

RAASB properties and treatment data are summarized in Tables 2 and 3. All patients had a localized disease at presentation, without distant metastases. Forty-seven (94\%) patients were operated on with curative intent, of whom $10(21 \%)$ were re-operated because of insufficient surgical margins (five insufficient margins not specified in the pathology report, three insufficient side and deep margins, one insufficient side margin, and one insufficient deep margin). The median pathological surgical margin was $2.0 \mathrm{~cm}$ (range 0-6.0). All patients had the skin of the breast and subcutaneous tissue excised. The surgical operation included the resection of the pectoral fascia and pectoral muscle in $70 \%$ and $32 \%$ of patients, respectively. Twenty-four $(51 \%)$ patients had a surgical reconstruction. The tissue defect was most commonly reconstructed with a pedicled latissimus dorsi flap with (seven patients) or without (eight patients) skin grafts. Three patients with RAASB were not operated on, two because of the extent of disease and impaired health, and one because of a metastatic BC. These three patients all died after a median of 44 days (range 23-58). 
TABLE 1 Breast cancer characteristics

\begin{tabular}{|c|c|c|}
\hline & $n=50$ & $\%$ \\
\hline \multicolumn{3}{|l|}{ Surgery type } \\
\hline Resection & 39 & 78 \\
\hline Mastectomy & 11 & 22 \\
\hline \multicolumn{3}{|c|}{ AJCC stage (8th edition) } \\
\hline IA & 30 & 60 \\
\hline IIA & 9 & 18 \\
\hline IIB & 8 & 16 \\
\hline IIIA & 2 & 4 \\
\hline IIIB & 1 & \\
\hline \multicolumn{3}{|l|}{ Histology } \\
\hline Ductal & 35 & 70 \\
\hline Lobular & 10 & 20 \\
\hline Mucinous & 2 & \\
\hline Tubular & 2 & \\
\hline Not assessed & 1 & \\
\hline \multicolumn{3}{|l|}{ Grade } \\
\hline 1 & 16 & 32 \\
\hline 2 & 26 & 52 \\
\hline 3 & 2 & 4 \\
\hline Not assessed & 6 & 12 \\
\hline \multicolumn{3}{|c|}{ Estrogen receptor } \\
\hline Positive & 38 & 76 \\
\hline Negative & 3 & 6 \\
\hline Not assessed & 9 & 18 \\
\hline \multicolumn{3}{|c|}{ Progesterone receptor } \\
\hline Positive & 31 & 62 \\
\hline Negative & 10 & 20 \\
\hline Not assessed & 9 & 18 \\
\hline \multicolumn{3}{|l|}{ HER2 status } \\
\hline Positive & 1 & 2 \\
\hline Negative & 20 & 40 \\
\hline Not assessed & 29 & 58 \\
\hline \multicolumn{3}{|c|}{ Adjuvant endocrine therapy } \\
\hline No & 32 & 64 \\
\hline Yes & 18 & 36 \\
\hline \multicolumn{3}{|c|}{ Adjuvant chemotherapy } \\
\hline No & 48 & 96 \\
\hline Yes & 2 & 4 \\
\hline
\end{tabular}

AJCC American Joint Committee on Cancer, HER2 human epidermal growth factor receptor 2

Five patients received postoperative chemotherapy, of whom three received paclitaxel, one received doxorubicin, and one received a taxane- and anthracycline-based regimen after an erroneous diagnosis of BC recurrence. This patient also received postoperative RT. The most common indication for postoperative chemotherapy was a large tumor size.

The treatment and outcome of patients operated with curative intent $(n=47)$ are summarized in Fig. 1 . The median follow-up time was 5.4 years (range 0.4-15.6). No patients were lost to follow-up, and $19(40 \%)$ patients were alive without any RAASB recurrence at last follow-up. A local recurrence of RAASB was diagnosed in 21 of 47 (45\%) patients after a median of 1.0 years (range $0.1-10.0) ; 19(90 \%)$ of these patients were operated on with curative intent, 6 of whom remained free of local and distant recurrence at last follow-up. One additional patient has been free of local and distant recurrence following surgery for a second local recurrence. The median margin, at surgery, of local recurrences was $1.0 \mathrm{~cm}$ (range 0.05-3.0). At the last follow-up, 7 (33\%) of the 21 patients with a local recurrence were alive without evidence of disease, $1(5 \%)$ was alive with a metastatic RAASB treated with paclitaxel, $1(5 \%)$ was alive with a metastatic RAASB, 11 (52\%) had died of RAASB, and 1 (5\%) had died of BC.

A distant metastasis of RAASB was diagnosed in 14 (30\%) patients after a median of 1.1 years (range $0.4-10.5), 8(57 \%)$ of whom had and $6(43 \%)$ did not have a preceding or simultaneous local recurrence. At last follow-up, 11 of these $14(79 \%)$ patients had died of metastatic RAASB and 3 patients were alive with a metastatic RAASB, 2 with no evidence of disease ( 4.4 and 5.1 years after the diagnosis of a metastatic RAASB to the lymph nodes and treatment with paclitaxel) and 1 with ongoing treatments for metastatic disease. The most common metastatic sites were the lungs $(n=8)$, liver $(n=4)$, and lymph nodes $(n=4)$. Four patients had multiple metastatic sites.

For operated patients $(n=47)$, the 5-year LRFS, DRFS, and OS rates were $62 \%, 75 \%$, and $74 \%$, respectively (Fig. 2). For all patients $(n=50)$, the 5- and 10-year OS rates were $69 \%$ and $52 \%$, respectively. Prognostic factors for survival in operated patients, determined using a Cox univariate analysis, are presented in Table 4. Only the planned surgical side margin (hazard ratio [HR] 0.419 per $\mathrm{cm}, 95 \%$ confidence interval $[\mathrm{CI}] 0.236-0.744 ; p=0.003$ ) was associated with the risk of death. There was a weak positive correlation between the planned surgical margin and the margin assessed by the pathologist $\left(R_{\mathrm{S}}=0.391\right.$; $p=0.059)$. None of the studied factors were significantly associated with local or distant recurrences, however there was a non-significant trend towards improved local control in patients operated with reconstructive surgery (HR 0.454, 95\% CI 0.182-1.133; $p=0.091$ ). 
TABLE 2 RAASB

characteristics
TABLE 3 Radiationassociated angiosarcoma of the breast treatment characteristics

\begin{tabular}{lll}
\hline & $n=50$ & $\%$ \\
\hline Age at RAASB diagnosis, years [mean (SD)] & 70.4 (SD 9.1) & \\
RAASB latency, years ${ }^{\mathrm{a}}$ [median (range)] & $7.7(0.6-24.5)$ & \\
Size based on histopathologic report, cm [median (range)] & $4.0(0.5-16.0)$ & 32 \\
Not assessed & 16 & 80 \\
Location & 40 & 10 \\
Breast & 5 & 10 \\
Mastectomy scar & 5 & 12 \\
Upper trunk & & 76 \\
Grade (according to the French system & \\
2 & 6 & 6 \\
3 & 38 & 6 \\
Not assessed & 6 & \\
\hline
\end{tabular}

$R A A S B$ radiation-associated angiosarcoma of the breast, $S D$ standard deviation

${ }^{a}$ RAASB latency was defined as the time from radiotherapy for breast cancer to RAASB diagnosis

\begin{tabular}{|c|c|c|}
\hline & $n=47$ & $\%$ \\
\hline Planned surgical side margin, $\mathrm{cm}$ [median (range)] & \multicolumn{2}{|c|}{4.0 (range $0.5-5.0$ ) } \\
\hline Not specified & \multicolumn{2}{|l|}{16} \\
\hline Pathological surgical margin, cm [median (range)] & \multicolumn{2}{|c|}{2.0 (range $0.0-6.0$ ) } \\
\hline Not assessed & \multicolumn{2}{|l|}{12} \\
\hline \multicolumn{3}{|l|}{ Surgically removed tissues } \\
\hline Skin of breast & 47 & 100 \\
\hline Subcutaneous tissue & 47 & 100 \\
\hline Mammary gland & 37 & 79 \\
\hline Pectoral fascia & 33 & 70 \\
\hline Pectoral muscle & 15 & 32 \\
\hline \multicolumn{3}{|l|}{ Reconstruction } \\
\hline No reconstruction & 23 & 49 \\
\hline Latissimus dorsi flap & 8 & 17 \\
\hline Latissimus dorsi flap with skin graft & 7 & 15 \\
\hline Pedicled transverse rectus abdominis myocutaneous flap & 2 & 4 \\
\hline Pedicled transverse rectus abdominis myocutaneous flap with skin graft & 1 & 2 \\
\hline Pedicled thoracolateral flap & 1 & 2 \\
\hline Only skin graft & 5 & 11 \\
\hline \multicolumn{3}{|l|}{ Postoperative radiotherapy } \\
\hline No & 46 & 98 \\
\hline Yes & 1 & 2 \\
\hline \multicolumn{3}{|l|}{ Postoperative chemotherapy } \\
\hline No & 42 & 89 \\
\hline Paclitaxel & 3 & 6 \\
\hline Doxorubicin & 1 & 2 \\
\hline Docetaxel and fluorouracil/epirubicin/cyclofosfamide ${ }^{\mathrm{a}}$ & 1 & 2 \\
\hline
\end{tabular}

${ }^{a}$ Erroneously diagnosed as breast cancer recurrence 


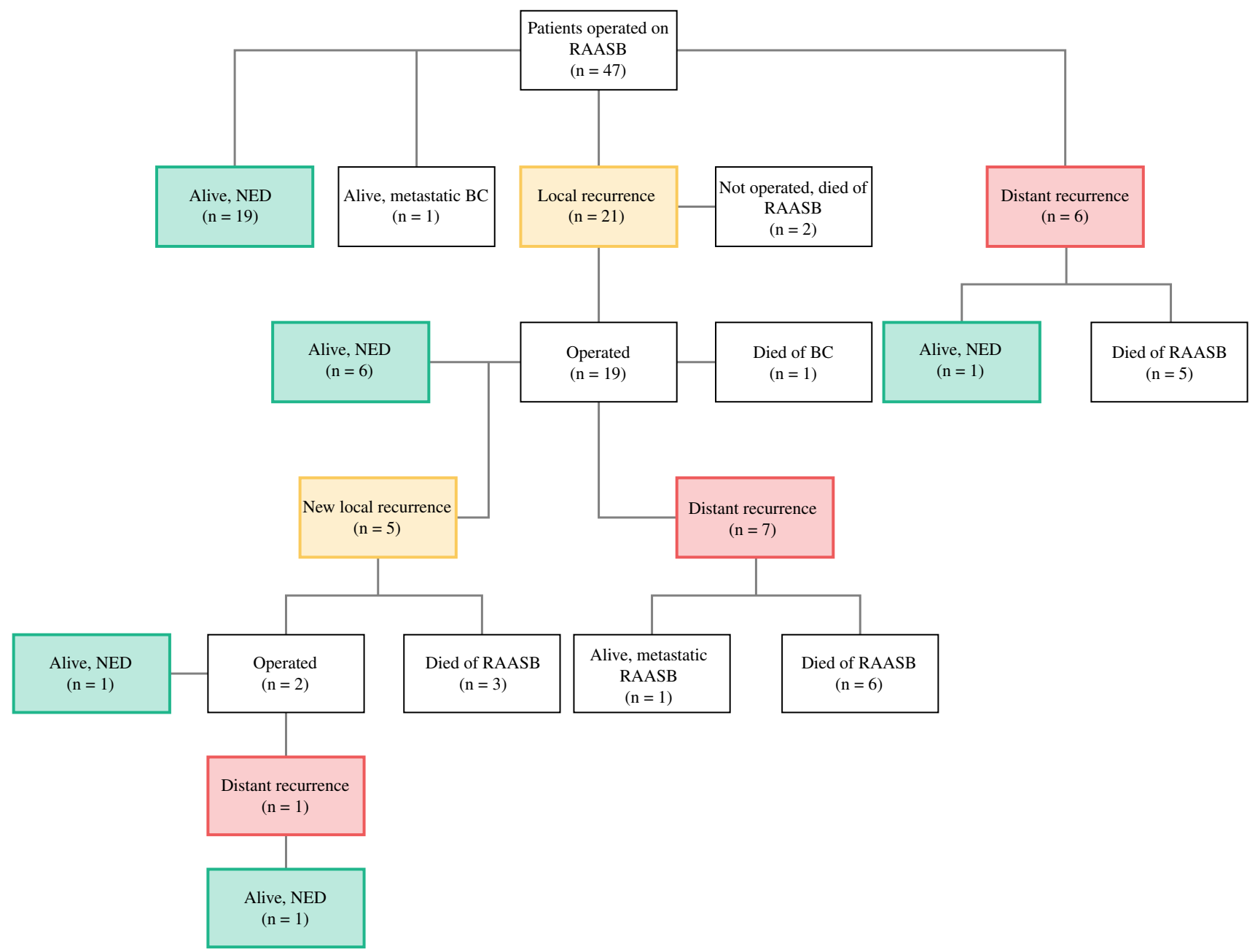

FIG. 1 Treatment and outcome of curatively treated RAASB patients. $B C$ breast cancer, $N E D$ no evidence of disease, $R A A S B$ radiationassociated angiosarcoma of the breast

\section{DISCUSSION}

Breast-conserving surgery and RT constitute the preferred local treatment of early BC. RAASB is a serious but fortunately uncommon complication of RT. The current study assessed RAASB treatment and prognosis in a nationwide population. We found that a radical surgical operation with curative intent is possible in the majority of RAASB patients. The 5- and 10-year OS rates of $69 \%$ and $52 \%$, respectively, compare favorably with previous studies, mostly institutional series, reporting 5-year OS rates of $10-75 \%,{ }^{8,10,12,20}$ and a recent large $(n=209)$ nationwide study reporting 5- and 10-year OS rates of $41 \%$ and $25 \%$, respectively. ${ }^{6}$ The large variation in survival is presumably derived from the diverse patient populations.

The primary treatment of localized RAASB is surgery. Awareness and early diagnosis of RAASB is crucial to enable surgical treatment with curative intent. In the present study, almost all patients (94\%) underwent surgery for
RAASB. The type of surgery, amount of removed tissues, and methods of surgical reconstruction varied considerably, reflecting the nationwide patient population and variable policies of treating hospitals. Previous research has emphasized the importance of extensive radical operations to improve survival. ${ }^{11,13}$ In a study of 38 RAASB patients, $36(95 \%)$ patients were operated on with curative intent, ${ }^{13}$ of whom 23 had a radical excision with surgical reconstruction and 13 had a non-radical excision. The authors observed a greater number of local recurrences in patients with $<1 \mathrm{~cm}$ margins, and concluded that at their institution, RAASB management currently involves a radical excision of the irradiated breast area. In a retrospective analysis from a tertiary center, a simple mastectomy alone was performed in 4 of 13 surgically treated patients. ${ }^{8}$ In the current study, the practice of removing the irradiated breast area was not followed. Instead, the surgical treatment consisted of a radical excision of the lesion with a median planned surgical side 

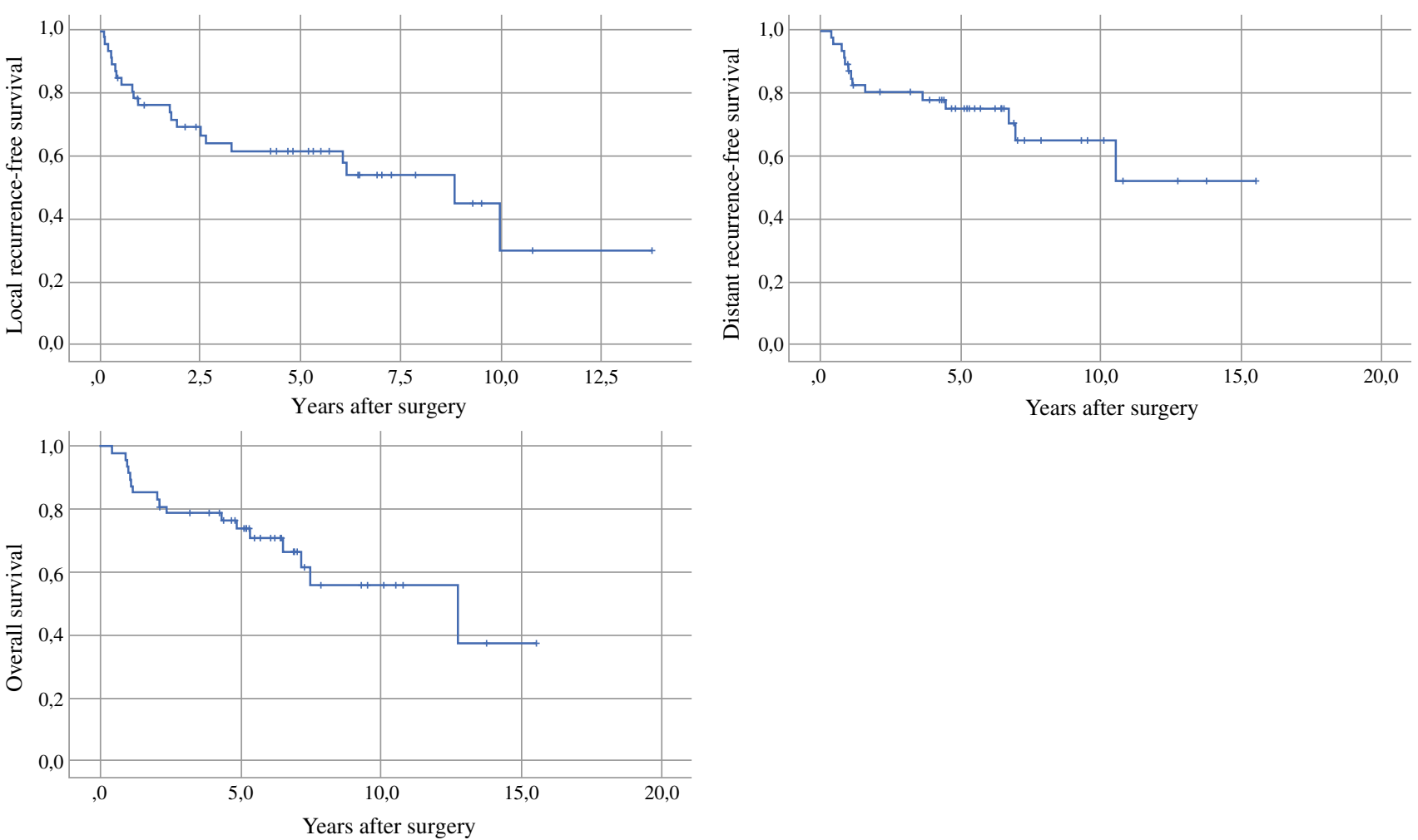

FIG. 2 Kaplan-Meier curves of local recurrence-free survival, distant recurrence-free survival, and overall survival in patients operated on with curative intent $(n=47)$

TABLE 4 Cox univariate analysis of hazard ratios for local recurrence-free survival, distant recurrence-free survival, and overall survival in radiation-associated angiosarcoma of the breast patients operated on with curative intent $(n=47)$

\begin{tabular}{|c|c|c|c|c|c|c|c|c|c|}
\hline & \multicolumn{3}{|l|}{ LRFS } & \multicolumn{3}{|l|}{ DRFS } & \multicolumn{3}{|l|}{ OS } \\
\hline & $p$ & HR & $95 \% \mathrm{CI}$ & $p$ & HR & $95 \% \mathrm{CI}$ & $p$ & HR & $95 \% \mathrm{CI}$ \\
\hline $\begin{array}{l}\text { Breast cancer surgery type (mastectomy } \\
\text { vs. resection) }\end{array}$ & 0.265 & 0.561 & $0.203-1.551$ & 0.829 & 1.181 & $0.261-5.337$ & 0.411 & 0.621 & $0.200-1.931$ \\
\hline Age at RAASB diagnosis ${ }^{\mathrm{a}}$ & 0.126 & 1.046 & $0.987-1.109$ & 0.187 & 1.048 & $0.978-1.123$ & 0.389 & 1.027 & $0.967-1.091$ \\
\hline Year of RAASB diagnosis ${ }^{\mathrm{a}}$ & 0.337 & 0.958 & $0.877-1.046$ & 0.169 & 1.097 & $0.961-1.253$ & 0.873 & 0.992 & $0.899-1.094$ \\
\hline RAASB latency (years) ${ }^{\mathrm{a}}$ & 0.691 & 1.022 & $0.918-1.139$ & 0.087 & 1.120 & $0.984-1.275$ & 0.160 & 1.093 & $0.965-1.238$ \\
\hline $\begin{array}{l}\text { Tumor size according to the pathologist's } \\
\text { report }(\mathrm{cm})^{\mathrm{a}}\end{array}$ & 0.814 & 1.014 & $0.906-1.134$ & 0.253 & 1.075 & $0.950-1.216$ & 0.413 & 1.054 & $0.929-1.196$ \\
\hline Grade (2 vs. 3 ) & 0.546 & 0.676 & $0.190-2.410$ & 0.379 & 25.914 & $0.018-36,636.3$ & 0.414 & 25.763 & $0.011-62,885$ \\
\hline Planned surgical side margin $(\mathrm{cm})^{\mathrm{a}}$ & 0.184 & 0.685 & $0.392-1.197$ & 0.470 & 0.796 & $0.429-1.477$ & 0.003 & 0.419 & $0.236-0.744$ \\
\hline $\begin{array}{l}\text { Surgical margin according to the } \\
\text { pathologist's report }(\mathrm{cm})^{\mathrm{a}}\end{array}$ & 0.558 & 0.906 & $0.650-1.262$ & 0.177 & 0.714 & $0.438-1.165$ & 0.090 & 0.677 & $0.431-1.063$ \\
\hline $\begin{array}{l}\text { Extent of surgery (only skin/subcutaneous } \\
\text { tissue vs. removal of muscle/fascia) }\end{array}$ & 0.260 & 0.591 & $0.237-1.475$ & 0.993 & 1.005 & $0.318-3.172$ & 0.283 & 0.581 & $0.215-1.568$ \\
\hline Reconstructive surgery (no vs. yes) & 0.091 & 0.454 & $0.182-1.133$ & 0.293 & 0.555 & $0.185-1.663$ & 0.266 & 0.567 & $0.209-1.540$ \\
\hline Postoperative radiotherapy (no vs. yes) & 0.686 & 0.048 & $0.000-120,815$ & 0.125 & 5.103 & $0.638-40.833$ & 0.119 & 5.232 & $0.654-41.850$ \\
\hline Postoperative chemotherapy (no vs. yes) & 0.993 & 1.007 & $0.230-4.407$ & 0.521 & 1.652 & $0.357-7.653$ & 0.235 & 2.170 & $0.604-7.805$ \\
\hline
\end{tabular}

$H R$ hazard ratio, $C I$ confidence interval, $L R F S$ local recurrence-free survival, DRFS distant recurrence-free survival, $O S$ overall survival, $R A A S B$ radiation-associated angiosarcoma of the breast

${ }^{\mathrm{a}}$ Continuous variable 
margin of $4.0 \mathrm{~cm}$. The removal of all the irradiated breast area may require extensive and mutilating surgical operations and surgical reconstruction. One study has suggested that radiation-associated sarcomas arise in or at the edge of the radiation field. ${ }^{21}$ This view was further supported by a recent study that proposed that RAASB "arise from a field change within the irradiated tissue". ${ }^{13}$ In the current study, the tissue defect was most often covered with pedicled latissimus dorsi flaps; however, detecting an RAASB recurrence can be more difficult if a pedicled flap is used. On the other hand, skin grafts may allow for a more reliable follow-up of the affected area.

We found that a larger planned surgical side margin was prognostic for OS, and there was also a non-significant trend towards an improved OS for the margin measured in the pathologist's report. The weaker association with the pathologist's assessment of the margin may reflect the difficulty in determining the extent of RAASB due to the multifocal growth pattern of RAASB, as previously postulated. $^{11}$ While surgical margins were not statistically significantly associated with local or distant recurrences, they showed weaker trends towards a better outcome, with wide CIs. Some previous studies have not found any association between the surgical margin and a local recurrence $^{9,14}$ or OS. ${ }^{20,22}$ On the other hand, a study including both primary and secondary angiosarcomas of the breast reported an improved OS for patients with negative surgical margins. ${ }^{23}$ Moreover, one study defining radical margins as removal of all or nearly all previous irradiated breast skin reported an improved 5-year diseasespecific survival of $86 \%$, versus $46 \%$ for radically versus conservatively operated patients. ${ }^{11}$ It is important to note that most individual studies, including the present study, are small, making assessment of prognostic factors unreliable. Due to its retrospective nature, the current study is missing information regarding the planned surgical side margin and pathological surgical side margin in a number of patients. It is important to bear in mind the possible bias in these results. A meta-analysis of published data comprising 222 RAASB patients reported that tumor size $(p<0.0005)$ and combination treatment with surgery and irradiation ( $p=0.01$ ) improved local control significantly, while tumor size $(p<0.0005)$, and age $(p=0.048)$, were prognostic for OS. ${ }^{24}$ Surgical margins were not assessed in this meta-analysis.

A notable finding in the current study was the high risk of local RAASB recurrence (45\%). Ninety percent of these patients underwent salvage surgery, and, at last follow-up, only 6 of $21(29 \%)$ patients remain alive without further recurrences. Previous investigations of RAASB have reported local recurrence rates ranging from 30 to $92 \%$ of patients. ${ }^{8,9,12-14,17}$ Unfortunately, only a few of these studies provide further follow-up data after local recurrence. In a study of 79 RAASB patients, only $25 \%$ of patients with a local recurrence later succumbed to RAASB. ${ }^{14}$ Therefore, the authors suggested an intensive treatment of local recurrences to improve survival. In another study, a local recurrence was found in 19 of 31 $(61 \%)$ patients, ${ }^{22}$ of whom 11 had a surgical excision of the recurrence, with a median survival of 34 months compared with 6 months in patients with no surgical intervention. Our results corroborate the previous findings and further support a radical surgical approach with curative intent in a local recurrence. In our institution, the follow-up plan also includes photographs of the affected area. The initial follow-up interval is short, with gradual prolongation if no recurrences occur.

In the current study, only one patient received postoperative RT and five patients received postoperative chemotherapy. In previous studies, the use of pre- or postoperative chemotherapy has ranged from $3 \%$ to $45 \%$ and no firm conclusions can be drawn regarding its beneficial impact. ${ }^{11,12,14,17,20,22}$ Administration of RT for RAASB is controversial due to the previously delivered RT for $\mathrm{BC}$ and the presumably RT-induced etiology of RAASB. In the literature, the application of pre- or postoperative RT has ranged substantially from 4 to $35 \% .^{10,12,20,25}$ Whether RT was administered pre- or postoperatively is often not declared. One study reported an improved disease-free survival at 2 years after adjuvant RT (explicit information on RT schedule was not disclosed), however both primary breast angiosarcoma and RAASB were included and the study population was small $(n=35) .^{25}$ In another population-based study of exclusively RAASB, no survival advantage was reported for patients managed with both surgery and RT compared with surgery alone. ${ }^{6}$

The results of our report are subject to at least three limitations. First, this was a retrospective study and it is possible that reporting to the nationwide cancer registry has been incomplete. However, this is unlikely because the FCR has an estimated coverage of $96 \%$ in all solid tumors and $82.9 \%$ in tumors of bone and soft tissues. ${ }^{26}$ Second, treatment policies may have changed during the study period. However, the year of RAASB diagnosis did not affect prognosis. Third, although relatively large, our patient population is underpowered to detect prognostic factors with a small or moderate impact. The most important strengths originate from the population-based patient cohort, systematic confirmation of RAASB from hospital and pathology records, and complete follow-up of all patients. RAASB treatment in Finland is mainly concentrated in the five university hospitals; however, some patients are treated in local hospitals. It is therefore possible that RAASB treatment protocols may differ and this may influence the results observed in this research. 


\section{CONCLUSIONS}

The present nationwide analysis of RAASB indicates that a radical resection with wide margins was achievable in most cases. The primary surgical intervention should aim at the best possible local control because a significant proportion of patients experiencing a local recurrence further develop a metastatic disease. The 5-year OS of $74 \%$ in surgically operated patients is higher than in most previous series. Planned excision with wide surgical margins was associated with an improved prognosis. The expected growth in the number of BC survivors may possibly lead to a further increase in RAASB incidence. Awareness of RAASB as a late side effect of RT for BC is essential to facilitate an early diagnosis, enable a radical surgical treatment, and eventually improve the prognosis. Consolidating RAASB treatment to high-volume centers is advisable to ensure quality of care.

ACKNOWLEDGMENTS Open access funding provided by University of Helsinki including Helsinki University Central Hospital. The authors thank the FCR for their collaboration.

AUTHOR CONTRIBUTIONS All authors contributed to the conception and design of the study, and data interpretation. SHS, MMS, and TOB contributed to data collection; SHS, TW, MMS, MT, LP, $\mathrm{ET}, \mathrm{KH}$, and CPB contributed to the data analysis; TW, MMS, MT, $\mathrm{LP}, \mathrm{TOB}, \mathrm{ET}, \mathrm{KH}$, and $\mathrm{CPB}$ provided clinical expertise; and SHS wrote the first draft of the paper. All authors contributed to the writing of the manuscript and approved the final version.

FUNDING This work was funded by the Competitive Research Funding of Helsinki University Hospital and the Finnish Cancer Society. These institutions had no role in the study design, data interpretation, or writing of the article.

AVAILABILITY OF DATA AND MATERIAL The datasets of the current study can be made available from the corresponding author upon reasonable request.

DISCLOSURE Samuli H. Salminen, Tom Wiklund, Mika M. Sampo, Maija Tarkkanen, Lea Pulliainen, Tom O. Böhling, Erkki Tukiainen, Katja Hukkinen, and Carl P. Blomqvist declare no conflicts of interest.

CONSENT FOR PUBLICATION This manuscript does not contain an individual's personal data, therefore consent for publication was not necessary.

OPEN ACCESS This article is distributed under the terms of the Creative Commons Attribution 4.0 International License (http://crea tivecommons.org/licenses/by/4.0/), which permits unrestricted use, distribution, and reproduction in any medium, provided you give appropriate credit to the original author(s) and the source, provide a link to the Creative Commons license, and indicate if changes were made.

\section{REFERENCES}

1. Bray F, Ferlay J, Soerjomataram I, Siegel RL, Torre LA, Jemal A. Global cancer statistics 2018: GLOBOCAN estimates of incidence and mortality worldwide for 36 cancers in 185 countries. CA Cancer J Clin. 2018;68(6):394-424.

2. Newman LA, Kuerer HM. Advances in breast conservation therapy. J Clin Oncol. 2005;23(8):1685-1697.

3. Early Breast Cancer Trialists' Collaborative Group, Darby S, McGale $\mathrm{P}$, et al. Effect of radiotherapy after breast-conserving surgery on 10-year recurrence and 15-year breast cancer death: meta-analysis of individual patient data for 10,801 women in 17 randomised trials. Lancet. 2011;378(9804):1707-1716.

4. Sheth GR, Cranmer LD, Smith BD, Grasso-Lebeau L, Lang JE. Radiation-induced sarcoma of the breast: a systematic review. Oncologist. 2012;17(3):405-418.

5. Salminen SH, Sampo MM, Bohling TO, Tuomikoski L, Tarkkanen M, Blomqvist CP. Radiation-associated sarcoma after breast cancer in a nationwide population: increasing risk of angiosarcoma. Cancer Med. 2018;7(9):4825-4835.

6. Rombouts AJM, Huising J, Hugen N, et al. Assessment of radiotherapy-associated angiosarcoma after breast cancer treatment in a dutch population-based study. JAMA Oncol. 2019;5(2):267-269.

7. Styring E, Fernebro J, Jonsson PE, et al. Changing clinical presentation of angiosarcomas after breast cancer: from late tumors in edematous arms to earlier tumors on the thoracic wall. Breast Cancer Res Treat. 2010;122(3):883-887.

8. Jallali N, James S, Searle A, Ghattaura A, Hayes A, Harris P. Surgical management of radiation-induced angiosarcoma after breast conservation therapy. Am J Surg. 2012;203(2):156-161.

9. Torres KE, Ravi V, Kin K, et al. Long-term outcomes in patients with radiation-associated angiosarcomas of the breast following surgery and radiotherapy for breast cancer. Ann Surg Oncol. 2013;20(4):1267-1274.

10. Yin M, Wang W, Drabick JJ, Harold HA. Prognosis and treatment of non-metastatic primary and secondary breast angiosarcoma: a comparative study. BMC Cancer. 2017;17(1):295.

11. Li GZ, Fairweather M, Wang J, Orgill DP, Bertagnolli MM, Raut CP. Cutaneous radiation-associated breast angiosarcoma: radicality of surgery impacts survival. Ann Surg. 2017;265(4):814-820.

12. Gervais MK, Burtenshaw SM, Maxwell J, et al. Clinical outcomes in breast angiosarcoma patients: a rare tumor with unique challenges. J Surg Oncol. 2017;116(8):1056-1061.

13. Feinberg L, Srinivasan A, Singh JK, et al. Impact of specialist management on survival from radiation-associated angiosarcoma of the breast. Br J Surg. 2018;105(4):401-409.

14. D'Angelo SP, Antonescu CR, Kuk D, et al. High-risk features in radiation-associated breast angiosarcomas. $\mathrm{Br} J$ Cancer. 2013;109(9):2340-2346.

15. Lindford A, Bohling T, Vaalavirta L, Tenhunen M, Jahkola T, Tukiainen E. Surgical management of radiation-associated cutaneous breast angiosarcoma. J Plast Reconstr Aesthet Surg. 2011;64(8):1036-1042.

16. Strobbe LJ, Peterse HL, van Tinteren H, Wijnmaalen A, Rutgers EJ (1998) Angiosarcoma of the breast after conservation therapy for invasive cancer, the incidence and outcome An unforseen sequela. Breast Cancer Res Treat. 1998;47(2):101-109.

17. Morgan EA, Kozono DE, Wang Q, et al. Cutaneous radiationassociated angiosarcoma of the breast: poor prognosis in a rare secondary malignancy. Ann Surg Oncol. 2012;19(12):3801-3808. 
18. Fritz AG PC, Jack A, Sobin LH, Parkin MD. International classification of diseases for oncology (ICD-O). Geneva: World Health Organization; 2000.

19. Coindre JM. Grading of soft tissue sarcomas: review and update. Arch Pathol Lab Med. 2006;130(10):1448-1453.

20. Mito JK, Mitra D, Barysauskas CM, et al. A comparison of outcomes and prognostic features for radiation-associated angiosarcoma of the breast and other radiation-associated sarcomas. Int J Radiat Oncol Biol Phys. 2019;104(2):425-435.

21. Neuhaus SJ, Pinnock N, Giblin V, et al. Treatment and outcome of radiation-induced soft-tissue sarcomas at a specialist institution. Eur J Surg Oncol. 2009;35(6):654-659.

22. Seinen JM, Styring E, Verstappen V, et al. Radiation-associated angiosarcoma after breast cancer: high recurrence rate and poor survival despite surgical treatment with R0 resection. Ann Surg Oncol. 2012;19(8):2700-2706.

23. McClelland S 3rd, Hatfield J, Degnin C, Chen Y, Mitin T. Extent of resection and role of adjuvant treatment in resected localized breast angiosarcoma. Breast Cancer Res Treat. 2019; 175(2):409-418.

24. Depla AL, Scharloo-Karels CH, de Jong MA, et al. Treatment and prognostic factors of radiation-associated angiosarcoma (RAAS) after primary breast cancer: a systematic review. Eur $J$ Cancer. 2014;50(10):1779-1788.

25. Ghareeb ER, Bhargava R, Vargo JA, Florea AV, Beriwal S. Primary and radiation-induced breast angiosarcoma: clinicopathologic predictors of outcomes and the impact of adjuvant radiation therapy. Am J Clin Oncol. 2016;39(5):463-467.

26. Leinonen MK, Miettinen J, Heikkinen S, Pitkaniemi J, Malila N. Quality measures of the population-based finnish cancer registry indicate sound data quality for solid malignant tumours. Eur $J$ Cancer. 2017;77:31-39.

Publisher's Note Springer Nature remains neutral with regard to jurisdictional claims in published maps and institutional affiliations. 